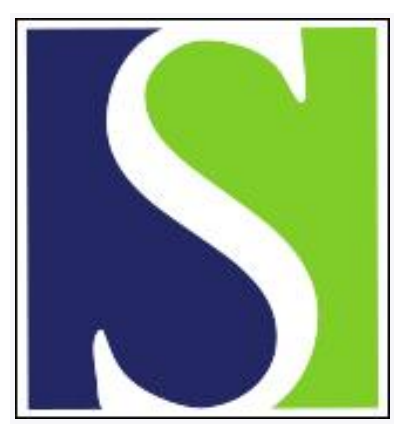

Scand J Work Environ Health 1985;11(2):111-115

https://doi.org/10.5271/sjweh.2245

Issue date: Apr 1985

Occurrence of airborne silicon carbide fibers during industrial production of silicon carbide.

by Bye E, Eduard W, Gjonnes J, Sorbroden E

This article in PubMed: www.ncbi.nlm.nih.gov/pubmed/4001899

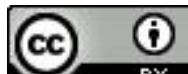




\title{
Occurrence of airborne silicon carbide fibers during industrial production of silicon carbide
}

\author{
by Erik Bye, PhD, ${ }^{1}$ Wijnand Eduard, MSc, ${ }^{1}$ Jon Gjønnes, PhD, ${ }^{2}$ Erik Sørbrøden, BSc ${ }^{2}$
}

\begin{abstract}
BYE E, EDUARD W, GJØNNES J, SØRBRØDEN E. Occurrence of airborne silicon carbide fibers during industrial production of silicon carbide. Scand $J$ Work Environ Health 11 (1985) 111-115. Airborne dust from the production of silicon carbide has been analyzed for particle morphology and composition. Fibers of alpha silicon carbide were identified by scanning electron microscopy (SEM) combined with energy dispersive X-ray spectrometry (EDS) and transmission electron microscopy (TEM) with selected area electron diffraction techniques (SAED). Micrographs taken at high magnification revealed several stacking periods along the fiber axis, and one or more of the polytypes $2 \mathrm{H}, 4 \mathrm{H}$, or $6 \mathrm{H}$ could be distinguished. Preliminary investigations applying SEM showed that $80 \%$ of the fibers had diameters of less than $0.5 \mu \mathrm{m}$ and a length greater than $5 \mu \mathrm{m}$. Fiber concentrations were examined by the counting of stationary and personal samples in an optical phase contrast microscope. The fiber levels in the three plants investigated were low and less than 1 fiber $/ \mathrm{cc}$ of air $\left(10^{6} \mathrm{fibers} / \mathrm{m}^{3}\right)$. Dust samples from the handling of raw material, including recycled material, contained up to 5 fibers $/ \mathrm{cc}\left(5 \cdot 10^{6}\right.$ fibers $\left./ \mathrm{m}^{3}\right)$.
\end{abstract}

Key terms: electron diffraction, electron microscopy, energy dispersive spectrometry, fiber concentrations, health hazard.

Silicon carbide $(\mathrm{SiC})$ is produced from quartz sand and petrol coke according to the following chemical reaction:

$$
\mathrm{SiO}_{2}+3 \mathrm{C}=\mathrm{SiC}+2 \mathrm{CO}
$$

with a maximum reaction temperature of $2300 \mathrm{~K}$. The work environment is quite complex; crystalline silica, polycyclic aromatic hydrocarbons (PAH), carbon monoxide, and sulfur dioxide being generally recognized as the primary chemical hazards (7). Silicon carbide dust has so far been considered less harmful and is characterized as a nuisance dust (2).

Although silicon carbide has a very simple chemical formula, the compound may exist in more than 150 different crystal modifications, based upon different stacking of the silicon and carbon layers (6). Furthermore, silicon carbide may exist also as whiskers or continuous fibers, in addition to ordinary isometric particles $(1,6)$. It has been demonstrated that the pleural instillation of silicon carbide fibers causes carcinoma in rat (8). In vitro cellular effects of silicon carbide fibers correlate well with the in vivo induction of pleural sarcoma $(5,9)$.

The presence of fibrous silicon carbide in the work environment during the production of the compound has not previously been reported. It is the aim of this paper to describe the identification and quantification of such airborne fibrous particles in three Norwegian silicon carbide plants.

1 Institute of Occupational Health, Oslo, Norway.

2 Institute of Physics, University of Oslo, Oslo, Norway.

Reprint requests to: Dr E Bye, Institute of Occupational Health, PO Box 8149 Dep, Oslo 1, Norway.

\section{Materials and methods}

Preliminary dust samples were collected on Nuclepore filters ( $37 \mathrm{~mm}$ diameter and $0.8 \mu \mathrm{m}$ pore size) with open-faced aerosol monitors and du Pont constant flow samplers (model P 2500). Stationary samples for fiber identification were collected at a flow rate of $1.9 \mathrm{l} / \mathrm{min}$ and with a sampling time of 5 min. Small pieces of the Nuclepore membranes were cut, coated with gold, and studied in a Jeol JSM-35 scanning electron microscope (SEM) equipped with a PGT-1000 X-ray microanalyzer (EDS). Additional pieces of the membrane were coated with carbon and attached to 200-mesh nickel electron microscopy (EM) grids. The grids were then placed on a polyurethane sponge soaked in chloroform in order to dissolve the membrane. The particles, left on a supporting carbon film, were examined in a Jeol $200 \mathrm{CX}$ transmission electron microscope (TEM) and subjected to selected area electron diffraction (SAED).

For comparison the silicon carbide fiber material used by Stanton \& Layard (8) and Lipkin (5) in their experiments was also examined.

Airborne dust samples for fiber counting were collected on Millipore AAWG membrane filters with open-faced aerosol monitors. Otherwise, the same procedure and equipment as have already been described were used. The sampling periods varied between 15 and $50 \mathrm{~min}$, being adjusted to obtain an optimal fiber density on the filters. Personal and stationary samples were collected at various workplaces in all three plants. Fibers were counted in an optical phase contrast microscope at $500 \times$ magnification, fibers with a $0.25-\mu \mathrm{m}$ diameter being resolved. 


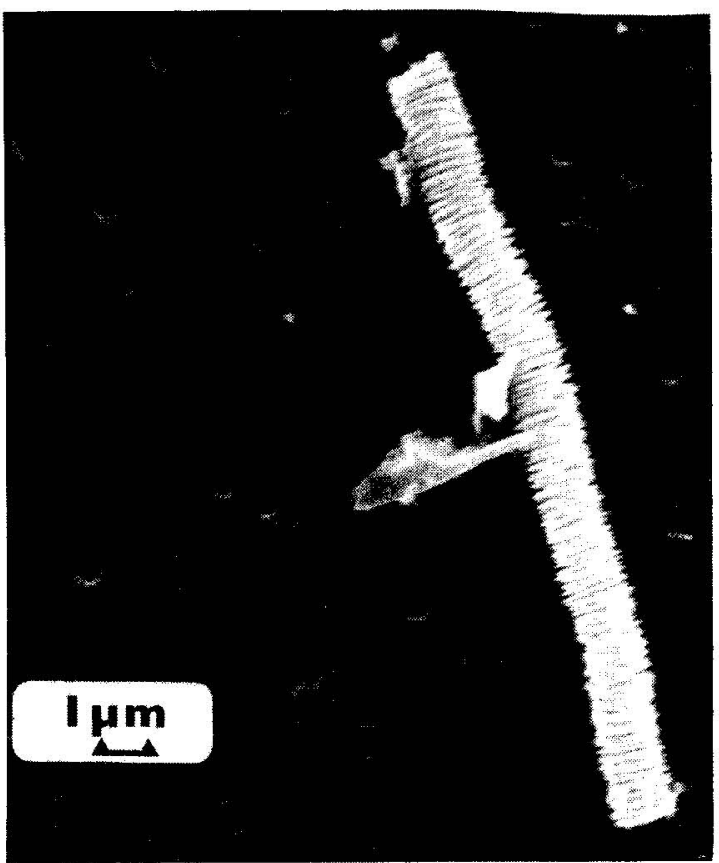

a

Figure 1. Typical airborne fibers from the production of silicon carbide as seen with scanning electron microscopy.

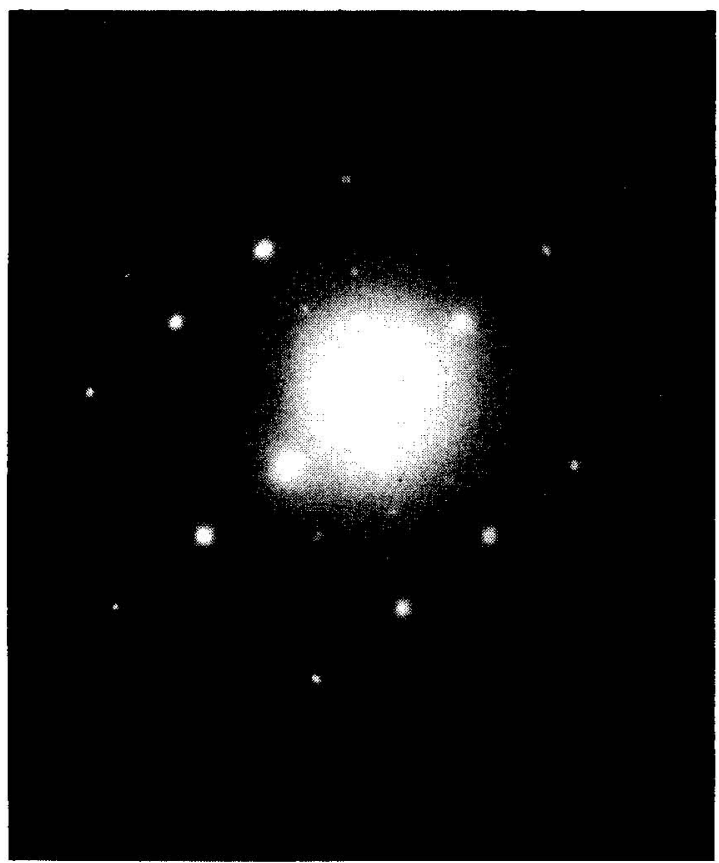

a

Figure 2. Electron diffraction pattern of the [110]-projection (a) and the [100]-projection (b)

Recycled material was examined with scanning electron microscopy and energy dispersive X-ray spectrometry.
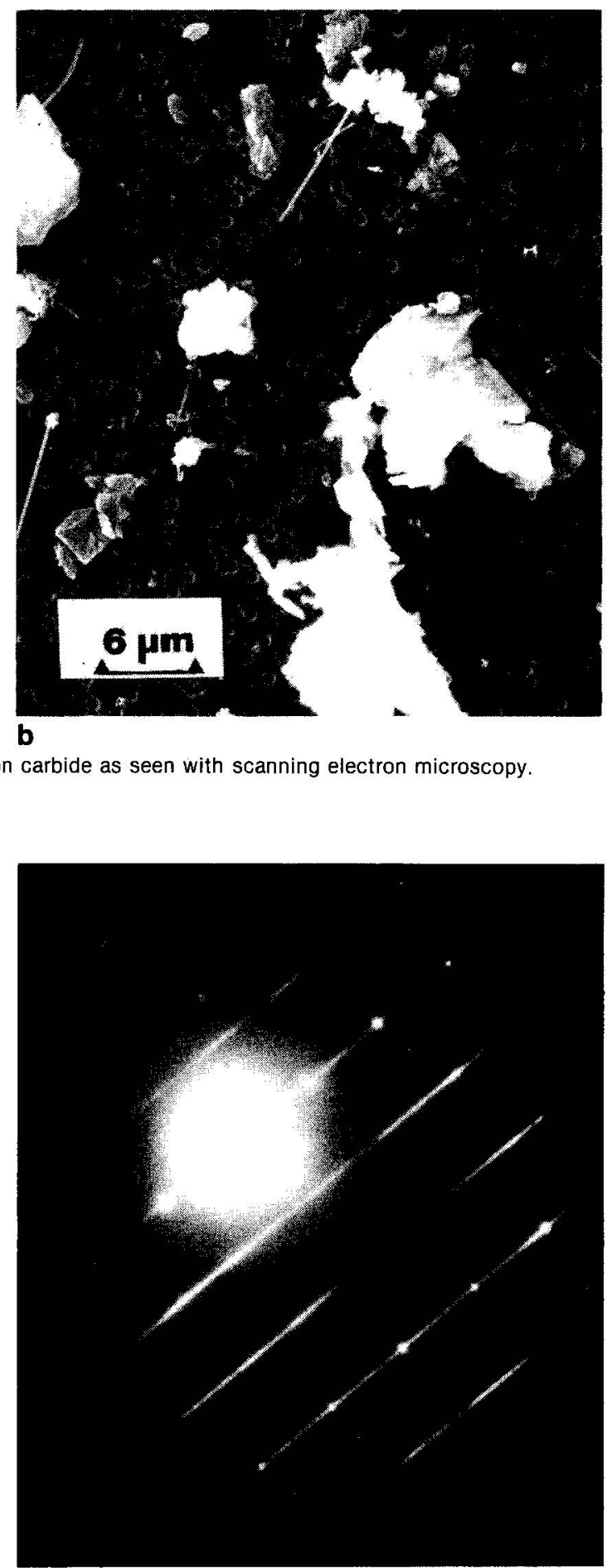

b
Results

Fibers of varying morphology were seen in all three plants. Most fibers were found during the mixing of 
the raw material, in the kiln house, and during separation of the crust. Fibrous particles, as observed in an SEM, are shown in figure 1. A corresponding EDS spectrum obtained in a TEM revealed only silicon, except for nickel originating from the EM grid.

One hundred and twenty-four fiber particles from 47 different dust samples were examined in an SEM. Eighty percent of the fibers had a diameter of less than $0.5 \mu \mathrm{m}$ and a length greater than $5 \mu \mathrm{m}$, the maximum length being $100 \mu \mathrm{m}$. Only fibers with an aspect ratio greater than ten were considered in the examination in order to ensure fibrous morphology.

Diffraction patterns from individual fibers, as shown in figure 2, revealed features characteristic of silicon carbide. With the beam along certain directions (eg, $[1 \overline{1} 0])$ only distinct reflections, which may belong to any of the different polytypes, are seen (figure 2a), ie, reflections with $\mathrm{h}-\mathrm{k}=3 \mathrm{n}$. When the incident beam is along other directions (eg, [100]), extensive streaking or dense rows of reflections parallel to the hexagonal axis are seen through reflections with $h-k \neq 3 n$ (figure $2 b$ ). From spots occurring on these streaks, we could sometimes distinguish periods indicating that one or more of the polytypes $2 \mathrm{H}, 4 \mathrm{H}$ or $6 \mathrm{H}$ was present - as described in the literature (6). The heavy streaking showed that extensive stacking disorder is always present, which is revealed in micrographs taken at high magnification. Several stacking periods are clearly seen in figure 3 .

Fibers of the same preparation as used by Stanton \& Layard (8) and Lipkin (5) in their experiments showed similar morphologies and diffraction pat- terns (figure 4). This specimen had a nominal diameter range of $0-1.0 \mu \mathrm{m}$ and a length range of $0-10 \mu \mathrm{m}$.

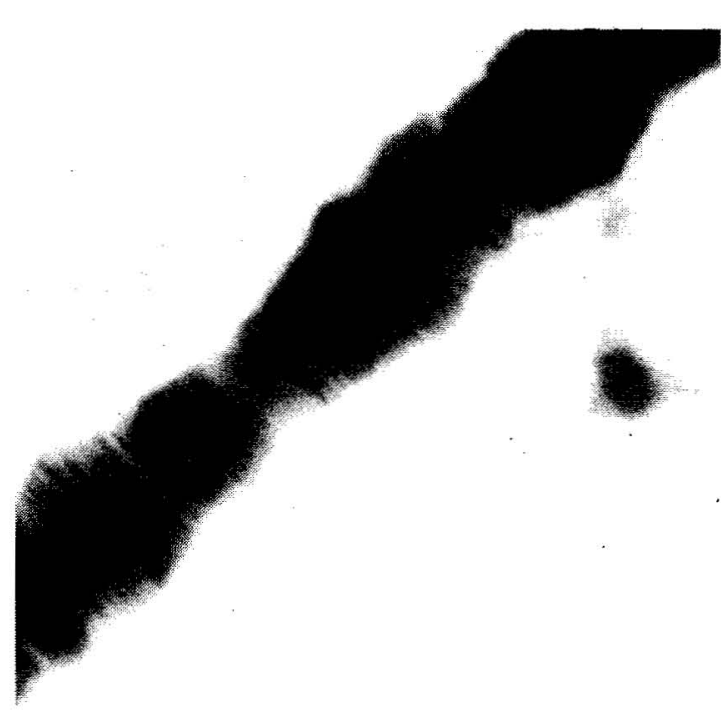

Figure 3. Alpha silicon carbide fiber as seen in a transmission electron microscope at $50000 \times$ magnification. Discrete lines perpendicular to the hexagonal $c$ axis reveal various polytypes along the fiber axis.

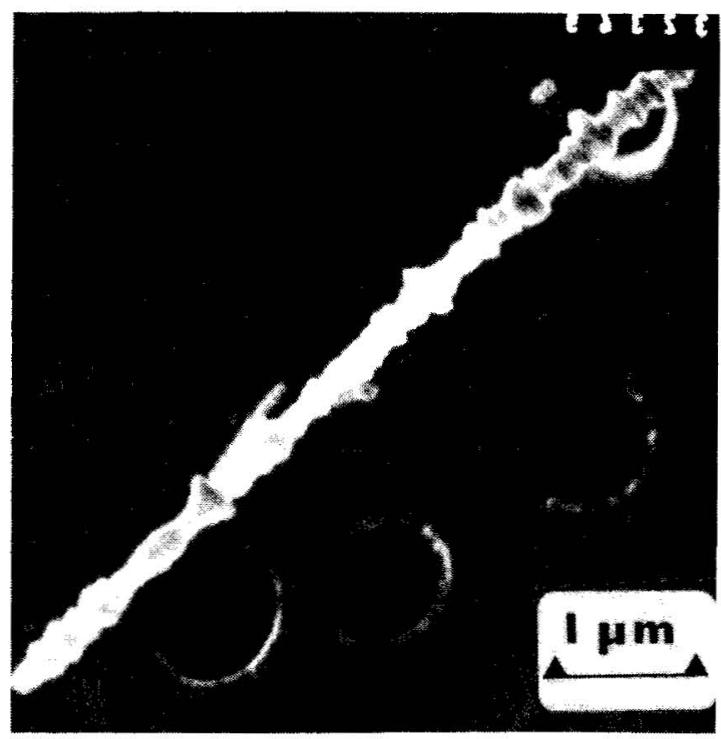

b

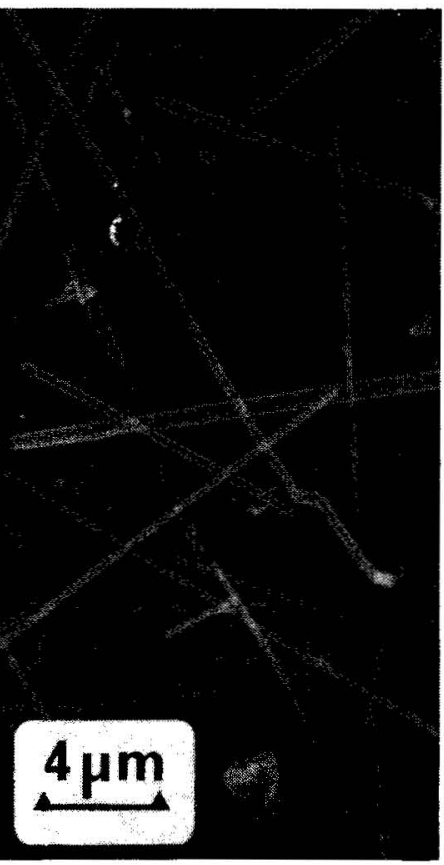

Figure 4. Alpha silicon carbide fibers used by Stanton \& Layard (8) and Lipkin (5) in their experiments, as seen in scanning (a) and transmission (b) electron microscopes. 


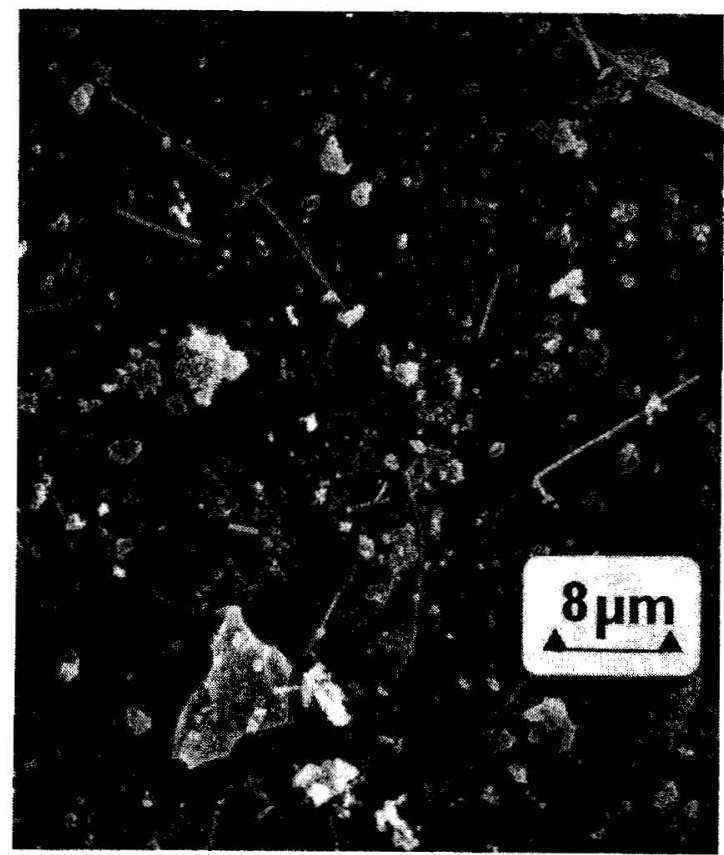

Figure 5. Fibrous particles from recycled material as observed with a scanning electron microscope.

Table 1. The concentrations of silicon carbide fibers as determined during comparable work operations. (Number of samples in parentheses)

\begin{tabular}{lcccc}
\hline \multirow{2}{*}{$\begin{array}{l}\text { Work } \\
\text { operations }\end{array}$} & \multicolumn{4}{c}{$\begin{array}{c}\text { Fiber concentrations in fibers/cc } \\
\left(10^{6} \text { fibers } / \mathrm{m}^{3}\right)\end{array}$} \\
\cline { 2 - 5 } & Plant A & Plant B & Plant C \\
\hline $\begin{array}{l}\text { Mixing of } \\
\text { raw material }\end{array}$ & 0.3 & (1) & $0.1-1.9(7)$ & $1.8-4.9(4)$ \\
$\begin{array}{l}\text { Furnace } \\
\text { operation }\end{array}$ & $0-3.6(16)$ & $0.1-1.9(4)$ & $0.1-0.7(7)$ \\
$\begin{array}{l}\text { Separation of } \\
\text { raw product } \\
\begin{array}{l}\text { Preparation of } \\
\text { final product }\end{array}\end{array}$ & $0.2-0.7(6)$ & $0.2-2.7(6)$ & 0.2 & $(3)$ \\
\hline
\end{tabular}

Table 2. Fiber dimensions of an airborne dust sample as evaluated in a scanning electron microscope. (100 fibers were evaluated.)

\begin{tabular}{lll}
\hline & $\begin{array}{c}\text { Geometric mean } \\
(\mu \mathrm{m})\end{array}$ & $\begin{array}{c}\text { Range } \\
(\mu \mathrm{m})\end{array}$ \\
\cline { 2 - 3 } Fiber diameter & 0.23 & $0.5-2.5$ \\
Fiber length & 4.5 & $1.0-50$ \\
\hline
\end{tabular}

No a-axis fibers were found. In a search for fibers with such an orientation we did find one single fiber with a different diffraction pattern. An EDS analysis showed an iron-containing particle, and the diffraction pattern could be indexed according to a reported unit cell of iron silicon carbide (4).

The observed fiber concentrations are given in table 1 . In general, the fiber concentrations were less

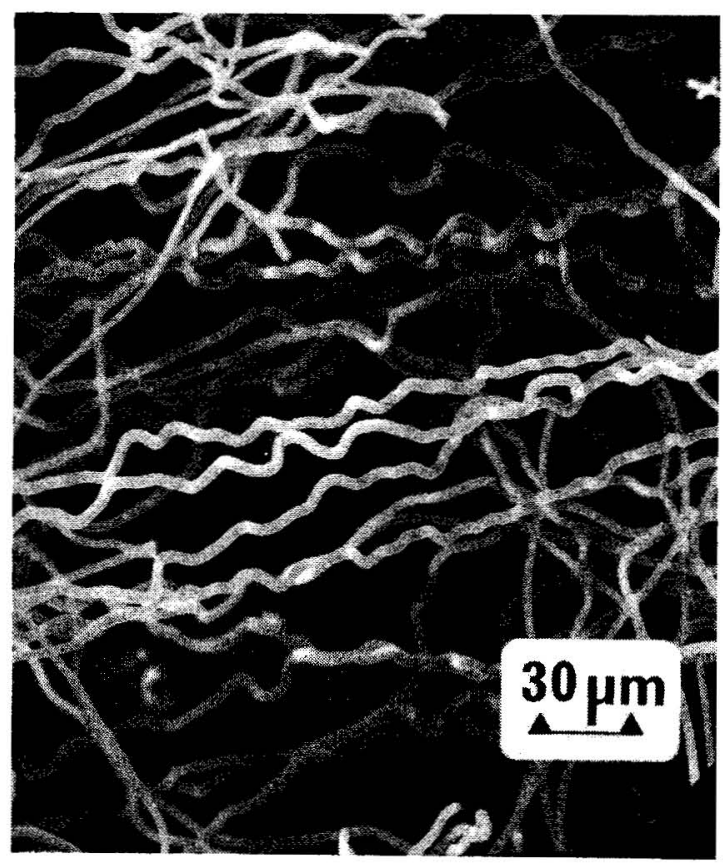

Figure 6. Woolly fibrous material from the crust surface as observed with a scanning electron microscope.

than 1 fiber $/ \mathrm{cc}\left(10^{6}\right.$ fibers $\left./ \mathrm{m}^{3}\right)$. The highest amounts of airborne fibers up to 5 fibers $/ \mathrm{cc}\left(5 \cdot 10^{6}\right.$ fibers $\left./ \mathrm{m}^{3}\right)$ were found during the mixing of the raw material. This finding is consistent with fibers frequently encountered in recycled material, which is visualized in figure 5 . EDS analysis revealed only silicon originating from the particles. Geometric mean values of diameter and length are listed in table 2 for one airborne dust sample.

Occasionally a woolly fibrous material was found on the surface of the reacted crust, as shown in figure 6. EDS analysis showed only silicon, whereas X-ray powder diffraction analysis gave no diffraction lines. These fibers are apparently thicker than those observed in the industrial atmosphere.

\section{Discussion}

The present study has shown that silicon carbide fibers are generated during the industrial production of silicon carbide. Diffraction patterns and electron micrographs revealed that several $\alpha$ silicon carbide polytypes may be present along the axis in each single fiber particle.

The high fiber concentration level during the handling of the raw material is consistent with fibers frequently encountered in recycled material. So far no fibrous particles have been observed in the final abrasive products, probably due to the crushing and flotation processes. However, fibers have been observed in products intended for refractory and metallurgical purpopes (firesand). Only occasionally were fiber 
concentrations above 1 fiber $/ \mathrm{cc}\left(10^{6}\right.$ fibers $\left./ \mathrm{m}^{3}\right)$ observed. The highest concentrations, as listed in table 1 , do not represent a time-weighted average of a full exposure shift but rather show that high fiber levels may occur over shorter periods. There are currently no epidemiologic data from groups exposed to silicon carbide fibers. However, the observed fiber concentrations may represent an occupational hazard, and, with regard to the animal experiments and the in vitro effects on macrophage-like cells, exposure to silicon carbide fibers may have effects comparable with those of other mineral and ceramic fibers. Furthermore, Funahashi et al (3) recently reported two cases of progressive dyspnea which was related to silicon carbide exposure in connection with the production of refractory bricks.

When evaluating the exposure risk in silicon carbide plants, one should distinguish between isometric and fibrous particles. Human exposure to such fibers should be avoided or reduced as far as possible until the health aspects have been fully explored.

\section{Acknowledgments}

The authors wish to thank Ms G Edholm and Ms L Overaae for their excellent technical assistance and Ms A Eide for patiently typing the manuscript. Mr J Jacobsen and Mr S Solvang are acknowledged for their cooperation and collection of the dust samples. The three Norwegian plants Arendal Smelteverk A/S, Norton A/S, and Orkla Exolon A/S \& Co are acknowledged for their interest and assistance in this project, and finally we thank Dr LE Lipkin for sharing some of Dr Stanton's silicon carbide fiber sample with us. This material was especially made for Dr Stanton by General Technologies Corp, Rescon, VA, USA.

\section{References}

1. Adamsky RF, Merz KM. Synthesis and crystallography of the wurtzite form of silicon carbide. Z Kristallogr 111 (1959) 350-361.

2. American Conference of Governmental Industrial Hygienists Inc. Documentation of the threshold limit values. Fourth edition. Cincinnati, OH 1983, p 366.

3. Funahashi A, Schlueter DP, Pintar K, Siegesmund KA, Mandel GS. Pneumoconiosis in workers exposed to silicon carbide. Am Rev Respir Dis 129 (1984) 635-640.

4. Jack KH. Comment in: Discussion on the paper - The structure of carbides in alloy steels: Part I - General survey by H.J. Goldschmidt. J Iron Steel Inst 163 (1949) $383-384$.

5. Lipkin LE. Cellular effects of asbestos and other fibres: Environ Health Perspect 34 (1980) 91-102.

6. Shaffer PTB. A review of the structure of silicon carbide. Acta Crystallogr B25 (1969) 477-488.

7. Smith TJ, Hammond SK, Laidlaw F, Fine S. Respiratory exposures associated with silicon carbide production: Estimation of cumulative exposures for an epidemiological study. Br J Ind Med 41 (1984) 100-108.

8. Stanton MF, Layard M. The carcinogenicity of fibrous minerals. In: National Bureau of Standards. Proceedings of the workshop on asbestos: Definitions and measurement methods. Gaithersburg, MD 1977, pp 143-151. (NSB special publication no 506).

9. Stanton MF, Layard M, Tegeris E, Miller E, May M, Morgan E, Smith A. Relation of particle dimension to carcinogenicity in amphibole asbestos and other fibrous materials. J Natl Cancer Inst 67 (1981) 965-975.

Received for publication: 5 December 1984 